\title{
Energy-efficient bioethanol recovery process using deep eutectic solvent as entrainer
}

\author{
Seong Chan Lee ${ }^{1} \cdot$ Hyeon Woo $\mathrm{Oh}^{1} \cdot$ Hee Chul Woo ${ }^{1} \cdot$ Young Han Kim ${ }^{1} \odot$
}

Received: 31 August 2021 / Revised: 8 November 2021 / Accepted: 7 December 2021

(c) The Author(s) 2021

\begin{abstract}
Bioethanol is commonly recovered from fermentation broth via distillation because it is the most economical and reliable process for large-scale industrial operations. Because extraction is a highly energy-efficient process applicable to low-composition bio-product separation, high-performance solvents are necessary for efficient bioethanol recovery. 2-Methyl pentanol, a branched long-chain alcohol, which was used as the extraction solvent, and a deep eutectic solvent, choline chloride and ethylene glycol (1:2), was employed as an entrainer for product refinement. Thermodynamic models of vapor-liquid equilibrium (VLE) and liquid-liquid equilibrium (LLE) systems were derived using molecular simulations and experimental results to develop the bioethanol extraction and refinement processes. The heat duty of the designed process was reduced by a quarter compared to that of previous recovery processes.
\end{abstract}

Keywords Bioethanol recovery $\cdot$ Deep eutectic solvent $\cdot$ Solvent extraction $\cdot$ Energy-efficient $\cdot$ Extractive distillation

\section{Introduction}

Bioethanol is a sustainable fuel used extensively in automobiles. Bioethanol recovery is generally achieved via distillation because it is the most economical and reliable solution for large-scale industrial operations. Distillation is suitable and has long been used for ethanol recovery because ethanol has a significantly lower boiling point than water, unlike other bio-alcohols [1]. However, as the distillation process consumes a large amount of energy, improvements are necessary to enhance sustainability [2-6]. The recovery of ethanol from bioethanol involves removing approximately $90 \%$ of the water from the feedstock. Various techniques can be implemented for ethanol-only recovery from low-ethanolcontent water mixtures, including membrane distillation $[7$, 8], supercritical extraction [9, 10], hybrid extraction/distillation [11-13], pressure swing adsorption [14-16], direct gasohol production [17], and extractive distillation [18-20].

Hee Chul Woo

woohc@pknu.ac.kr

Young Han Kim

yhkim2@pknu.ac.kr

1 Department of Chemical Engineering, Pukyong National University, 365 Shinsun-ro, Nam-gu, Busan 48547, South Korea
Extraction is a favorable recovery process owing to its low energy demand. Although the solvent recycling step in this process requires energy, an efficient solvent with a low solvent-to-feedstock ratio and a sufficiently large boilingpoint difference with the product can reduce the energy demand. Extraction can be performed with high efficiency at room temperature without heating, and recycling a lowtemperature solvent provides heat recovered from the hightemperature recycled solvent drawn from the solvent recovery column. Extraction is an established technique that has undergone substantial design and operation advancements. Therefore, the practical application of a new solvent can lead to improvements when it is developed using a known liquid-liquid equilibrium (LLE) model [21].

The high affinity between ethanol and water that gives rise to its azeotrope makes it difficult to produce ethanol with a purity of over $95 \%$. Either extractive or azeotropic distillation [22-25] can be applied to produce pure ethanol, but azeotropic distillation consumes more energy because of the high vapor flow in the rectifying section of the distillation column. Benzene and cyclohexane are used for azeotropic distillation, while ethylene glycol, glycerin, and deep eutectic solvents (DESs), such as choline/ethylene glycol [26, 27], choline/urea [28-30], and choline/glycerol [31], are suitable for extractive distillation. A comparison of the energy demands of various ethanol recovery processes 
indicates that extractive distillation is preferable for ethanol concentration.

In this study, 2-methyl pentanol was utilized for ethanol extraction from a $10 \%$ ethanol fermentation broth, and ethanol concentration was achieved via extractive distillation using a DES, namely, choline/ethylene glycol (1:2). The energy efficiency of the developed system was compared to those of existing processes applied to the same ethanol feedstock to demonstrate superior performance of the former. A similar procedure was applied for the production of 2,3-butanediol [32], ethanol [13], and butanol [33] from fermented feedstock.

\section{Solvent selection}

The proposed bioethanol recovery process encompasses one extractor and three distillation columns. Most of the water is removed from the feedstock via the extraction step and first distillation, and the two subsequent extractive distillations purify the pre-processed ethanol. Two solvents, 2-methyl pentanol and a DES, were used during the recovery process. Generally, distillation is employed for the pre-processing of low-content ethanol, whereas in this study, extraction was applied for this purpose [34]. The processed ethanol was purified in the next extractive distillation step using choline chloride/ethylene glycol at a molar ratio of 1:2. The suitability of choline chloride as an entrainer for the ethanol/ water azeotrope has been proposed and experimentally demonstrated in a previous study [35].

There are three major requirements an extraction solvent must satisfy: (1) high selectivity toward ethanol, (2) low solubility in water, and (3) a sufficient difference between its boiling point and that of ethanol [36]. Overall, 2-methyl pentanol is proposed as an optimal solvent for ethanol extraction considering the toxicity of higher alcohols and the boiling point requirement. The wastewater from the extraction process contains a small amount of the extraction solvent, which is recycled in the ethanol fermentation process [37], as in most bio-processes; hence, its toxicity to microorganisms must be considered.

\section{Thermodynamic models}

The proposed ethanol recovery process was developed using Aspen Plus ver. 8.8, which uses vapor-liquid equilibrium (VLE) and LLE models for thermodynamic computations.

\subsection{NRTL model}

Although the design of the extraction and distillation processes can be readily achieved using the commercial design software Aspen Plus [38], its database does not contain thermodynamic information for 2-methyl pentanol and DES. For VLE and LLE computations, the non-random two-liquid (NRTL) model [39] was used, and molecular simulations were conducted to obtain the equilibrium data because experimental measurements were not available. Because the extraction process is crucial in the proposed system, several LLE data were experimentally obtained to evaluate the validity of the simulated LLE results [13].

The parameters of the NRTL model were estimated from the experimental and molecular simulation results, and the activity coefficients were calculated using the following relationship:

$\ln \gamma_{i}=\frac{\sum_{j=1}^{N} \tau_{j i} G_{j i} x_{j}}{\sum_{k=1}^{N} G_{k i} x_{k}}+\sum_{j=1}^{N} \frac{x_{j} G_{i j}}{\sum_{l=1}^{N} G_{l j} x_{l}}\left[\tau_{i j}-\frac{\sum_{m=1}^{N} \tau_{m j} G_{m j} x_{m}}{\sum_{k=1}^{N} G_{k j} x_{k}}\right]$

where $N$ is the component number and $x_{\mathrm{j}}$ is the liquid composition of the jth component. The binary interaction parameters $\left(a_{\mathrm{ji}}\right.$ and $\left.b_{\mathrm{ij}}\right)$ and non-randomness factors $\left(\alpha_{\mathrm{ji}}\right)$ were used as the parameters in the above model:

$\tau_{j i}=a_{j i}+b_{j i} / T$

$G_{j i}=\exp \left(-\alpha_{j i} \tau_{j i}\right)$

The relation between vapor and liquid systems is given by:

$\gamma_{i} x_{i} P_{i}=\varphi_{i} y_{i} P^{T}$

where $P_{i}$ is the pressure of pure component $i$ at absolute temperature $T$, and $P^{\mathrm{T}}$ is the system pressure. $\varphi_{\mathrm{i}}$ is the fugacity coefficient and $y_{\mathrm{i}}$ is the vapor composition.

\subsection{Molecular simulations}

The feedstock components were water and ethanol, and two solvents, 2-methyl pentanol and a DES, were utilized for extraction and extractive distillation, respectively. The binary interaction parameters of the VLE system among water, ethanol, and ethylene glycol are available in the Aspen Plus database, but those of 2-methyl pentanol and the DES are not. For the VLE system, DES-related binary parameters are given in [27]. Therefore, 2-methyl pentanol-related VLE and LLE parameters were estimated using molecular simulation results [13].

The LLE binary parameters were estimated based on the molecular distribution in two liquid phases, computed using molecular simulations to determine the minimum potential among the constituent molecules in the respective liquid phases. The liquid phase was assigned as a cube in the molecular simulation. The force fields in molecular systems 
consist of intramolecular and intermolecular potentials; the former includes bond stretching, angle bending, and torsion, and the latter includes van der Waals and Coulomb forces, and are thus calculated as follows [40]:

$$
\begin{aligned}
U(\boldsymbol{r})= & \frac{1}{2} \sum_{\text {bonds }} k_{i j}^{r}\left(r_{i j}-r_{e q}\right)^{2}+\frac{1}{2} \sum_{\text {bend angles }} k_{i j k}^{\theta}\left(\theta_{i j k}-\theta_{e q}\right)^{2} \\
& +\frac{1}{2} \sum_{\text {torsion angles } m} \sum_{i j k l}^{\varphi, m}\left[1+\cos \left(m \varphi_{i j k l}-\gamma_{m}\right)\right] \\
+ & \sum_{i=1}^{N} \sum_{j=i+1}^{N}\left(4 \varepsilon_{i j}\left[\left(\frac{\sigma_{i j}}{r_{i j}}\right)^{12}-\left(\frac{\sigma_{i j}}{r_{i j}}\right)^{6}\right]+\frac{q_{i} q_{j}}{4 \pi \varepsilon_{0} r_{i j}}\right)
\end{aligned}
$$

where $\boldsymbol{r}$ is the spatial location of a molecule, $r_{i j}$ is the distance between atoms $i$ and $j$ in adjacent molecules, and $k$ is the potential constant [41]. The bend angle $(\theta)$ and torsion angle $(\varphi)$ are with respect to the reference axis and plane, respectively [40]. The constants $\varepsilon, \sigma$, and $q$ in the last term are for specific atoms. Molecular simulations determine the molecular distribution in the two boxes, which in turn reveals the compositions of the two phases at equilibrium. There are numerous parameters in the simulation that significantly affect the simulation results. By using the experimental LLE data in a reference system consisting of various solvents, the tuning parameter was adjusted to its optimum value for the proposed LLE system. The molecular simulation was conducted using RASPA, an open software, the installation details of which are explained in the installation and simulation manual [42]. RASPA performance is discussed in [43], and an example of the input file used in the simulation is listed in File S1 of the Supplementary Material. In the file, the TranslationProbability, RotationProbability, ReinsertionProbability, and GibbsSwapProbability parameters are adjustable; among them, GibbsSwapProbability was the most important for our application. Considering previous molecular simulation studies wherein LLE was applied in butanol and 2,3-butanediol extractions [32, 33], a value of 0.05 was deemed optimal in the LLE simulation, while the other parameters were set to the values in the file. In this study, phase transition probability was selected as an adjustable tuning parameter, while all other parameters were kept constant during the simulation. The molecular simulation results were partially compared with the experimental results to examine their accuracy. Similarly, the molecular distributions in the vapor and liquid phases were obtained from the potential computation, and the VLE data were used to estimate the VLE binary interaction parameters [44-46]. The liquid compositions at equilibrium determined using molecular simulation were compared with the experimental results obtained in [13]. Although numerous studies [32, 33, 47] have implemented molecular simulations for establishing the thermodynamic and physical properties of various compounds, the reliability of the results is generally inadequate. In particular, process designs that necessitate large investments toward plant construction require experimental verification of the computed results.

\section{Process design}

The proposed process consists of two stages: (1) water removal via extraction and (2) ethanol refinement via extractive distillation. Because no single solvent is suitable for both these processes, different solvents were used for each stage in this study. 2-Methyl pentanol was used as the water removal solvent, considering its water solubility and boiling point. A DES consisting of choline chloride/ethylene glycol (1:2) was used for ethanol concentration, as previously reported [26, 27]. Figure 1 illustrates a simplified scheme of the proposed bioethanol recovery process. The process was designed using Aspen Plus ver. 8.8.

The feed contained $10 \%$ ethanol, and the targets for ethanol purity and recovery were $99 \%$ and $98 \%$, respectively. The tray number for the extractor was determined for bioethanol recovery. The distillation columns were optimized in terms of their minimum total annualized cost (TAC), which is a combination of investment and operating costs. The cost equations used are reported in the literature [48, 49], and a cost index of 1638.2 (the Marshall and Swift equipment cost index in 2018) was used. The payback time for the investment was 10 years, and the number of annual operation days was 300 . Optimization was conducted using the response surface method [50].

\section{Results and discussion}

The thermodynamic parameter estimation, process design, and performance evaluation results are presented below.

\subsection{NRTL parameters}

Figure 2 shows a ternary diagram for water/ethanol/2-methyl pentanol. The plus (+) symbols and squares represent the molecular simulation and experimental results, respectively [13]; the circles represent the values computed using the NRTL model and the estimated parameters listed in Table 1; and the multiplication symbols are the Aspen Plus computed values. The connecting curves are the LLE compositions computed using the NRTL model. Agreement between the NRTL computation and Aspen Plus estimation ensures that Aspen Plus process design is supported by experimental and molecular simulation results. The LLE data are listed in Table S1 of the Supplementary Material, and the standard deviation was 0.0026. In the design of the LLE measurement experiment, the feed composition should provide a system of liquid-liquid separation. A preliminary ternary diagram 
Fig. 1 A simplified schematic diagram of the proposed bioethanol recovery process
Fig. 2 Ternary diagram of the water/ethanol/2-methyl pentanol system. The plus (+) symbols indicate the molecular simulation results, squares represent the experimental values, and circles are the values computed using the NRTL model. The multiplication symbols are the Aspen Plus computed values, and their connecting curves are the computed LLE compositions
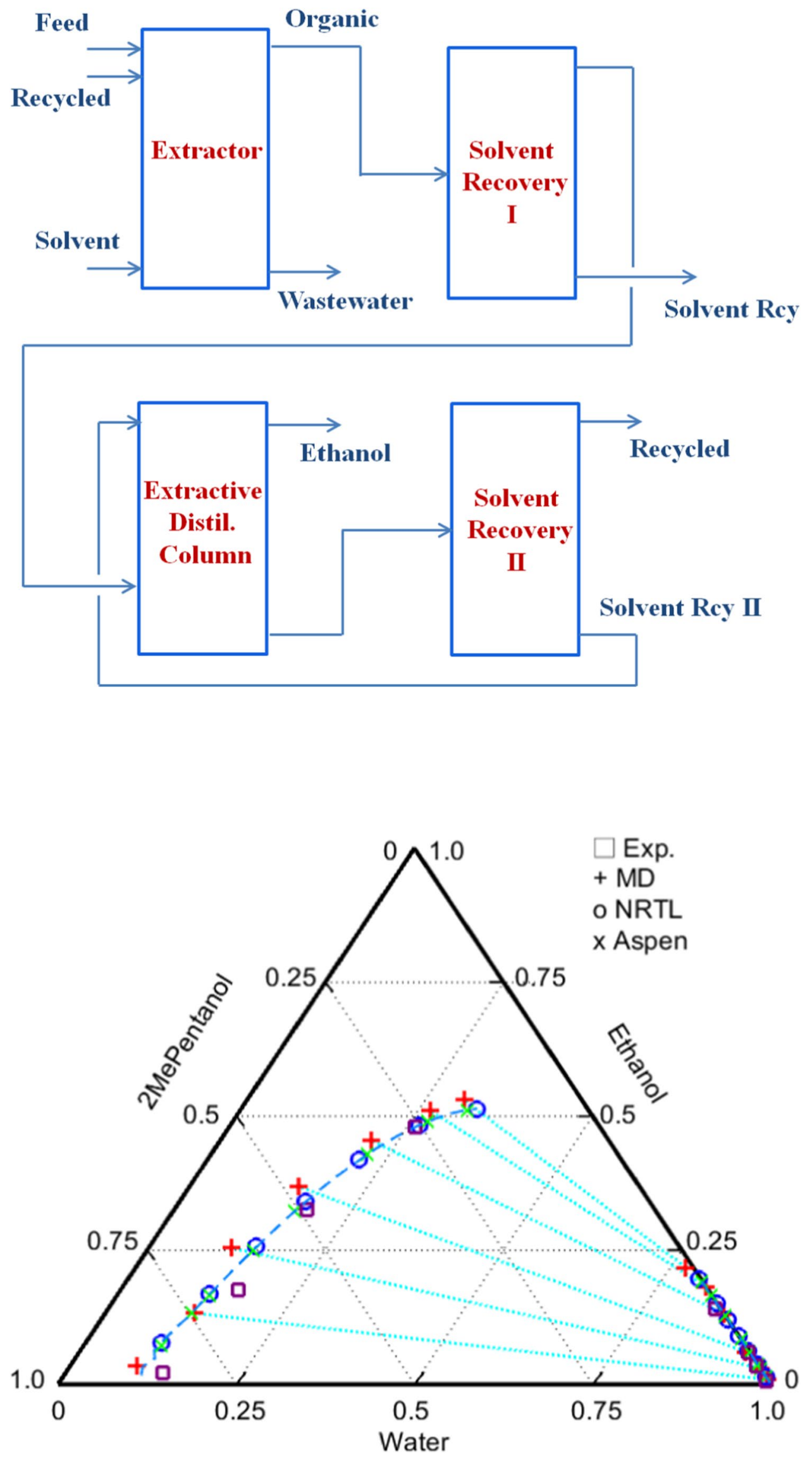
Table 1 Binary interaction parameters in the LLE and VLE NRTL models

\begin{tabular}{lllllcccc}
\hline System & Component $i$ & Component $j$ & $a_{i j}$ & $a_{j i}$ & $b_{i j}$ & $b_{j i}$ & $\alpha$ & Ref \\
\hline LLE & Water & Ethanol & 0 & 0 & 625.4889 & 29.934260 .3 & \\
& Water & 2-Methyl pentanol & 0 & 0 & 3365.368 & 462.9375 & 0.2 & \\
& Ethanol & 2-Methyl pentanol & 0 & 0 & 446.6883 & -84.764 & 0.3 & \\
VLE & Water & Ethanol & 3.622 & -0.922 & -636.726 & 284.2856 & 0.3 & {$[38]$} \\
& Water & Ethylene glycol & 0.3184 & 0.0531 & 33.2772 & -174.464 & 0.3 & {$[38]$} \\
& Water & 2-Methyl pentanol & 0 & 0 & 866.2356 & 287.6803 & 0.3 & \\
& Water & Choline chloride & 0 & 0 & -28.737 & -623.89 & 0.3 & {$[27]$} \\
& Ethanol & Ethylene glycol & 14.1741 & 0.3021 & -4440.97 & 20.1445 & 0.47 & {$[38]$} \\
& Ethanol & 2-Methyl pentanol & 0 & 0 & 84.4 & 105.9 & 0.3 & \\
& Ethanol & Choline chloride & 0 & 0 & 989.9 & -177.8 & 0.3 & {$[27]$} \\
& Ethylene glycol & 2-Methyl pentanol & 0 & 0 & 873.282 & -240.045 & 0.3 & \\
Ethylene glycol & Choline chloride & 0 & 0 & 94.193 & -227.56 & 0.3 & {$[27]$} \\
\hline
\end{tabular}

constructed using the molecular simulation results was used to determine the feed compositions on the tie lines of the split liquid phases. The curve computed using the NRTL model agreed well with the molecular simulation and experimental results. The LLE results of the molecular simulation and NRTL prediction of the water/ethanol/2-methyl pentanol system are summarized in Table S2 of the Supplementary Material. The mean deviation between the molecular simulation results and the predicted NRTL values was 0.0127 .

The VLE parameters of the system consisting of water/ ethanol/choline chloride/ethylene glycol listed in Table 1 were obtained from the Aspen Plus database and reported in [27]. The 2-methyl pentanol parameters were estimated from the VLE distribution predicted by molecular simulations. As a demonstration of the VLE molecular simulation results, the Txy diagram for the ethanol/2-methyl pentanol system is illustrated in Fig. S1 of the Supplementary Material. The circles and plus $(+)$ symbols of the ethanol liquid and vapor compositions agree well with the curves computed using the NRTL parameters. The VLE values obtained from molecular simulations and NRTL calculations are summarized in Table S3 of the Supplementary Material, and the mean deviation in the ethanol vapor composition was 0.0121 .

\subsection{Design results}

The design parameters of the column structure and operating conditions for the proposed process are listed in Table 2. Figure 3 illustrates the entire design process, showing the material and energy flows among the extractor and distillation columns, including their structural information. In Aspen Plus process design, the reflux flow was adjusted to establish the specified product specification with a fixed tray number and column operating pressure. The tray numbers were TAC optimized for achieving an ethanol recovery of $98.3 \%$ and purity of $99.3 \%$. The composition profiles of the organic phases in the extractor are shown in Fig. S2 of the
Supplementary Material. The extract composition indicates high ethanol content at the top of the extractor, as shown in the figure, and the extract was composed of mostly ethanol and solvent. The low ethanol content at the bottom of the extractor is related to the LLE composition of the aqueous phase, as shown in Fig. 2, and is indicative of minimal ethanol loss into the wastewater from the extractor. The ethanol recovery set by the process design objectives is related to the loss, and the number of extractor stages was determined as the design target. To improve ethanol recovery, the solvent flow rate must be increased, which in turn increases the equipment size and energy demand. In this study, a recovery of $98.3 \%$ was selected, avoiding significant solvent flow increments and loss of ethanol. Recently reviewed bioethanol dehydration processes reported purities of 99.2-99.9\% [51]. Although an initial solvent charge is necessary as holdup in the extractor, a small amount of solvent make-up is required, resulting in minimized process costs. The diameter of the designed extractor was $1.13 \mathrm{~m}$, as determined using design guidelines [52], and the height was $7.3 \mathrm{~m}$, based on two-foot tray spacing.

Bioethanol is fermented from grains, which necessitates the use of copious quantities of water. Wastewater can only be recycled in the fermentation process if the extraction solvent is non-toxic to fermentation microorganisms. The toxicity of 2-methyl pentanol is classed as Category 4 [53]. A toxicity study on yeast found that low-molecular-weight alcohols inhibited yeast growth at high concentrations [54]. Although these solvents inhibited yeast growth at saturation, they were partially or non-inhibitory at concentrations lower than $10 \%$ saturation [55]. While the solubility of 2-methyl pentanol is $0.31 \%$, its content in the wastewater was less than $0.01 \%$; thus, the toxicity was not a concern for the recycling step. Recycling the wastewater minimizes product loss and maximizes recovery. The extraction process removes $97 \%$ of the water from the feed, leading to lower energy consumption in the subsequent distillation process. 
Table 2 Structural information and operating conditions used in the proposed process. The tray numbers are counted from the top

\begin{tabular}{|c|c|c|c|c|}
\hline Variable & Extractor & SolvRec I & Extract. Dist & SolvRec II \\
\hline \multicolumn{5}{|l|}{ Structural } \\
\hline Tray no & 39 & 32 & 22 & 11 \\
\hline Feed & 1 & 13 & 20 & 5 \\
\hline Solvent & 39 & & 2 & \\
\hline Recycle & 2 & & & \\
\hline Operating pressure $(\mathrm{MPa})$ - top & 0.1 & 0.1 & 0.1 & 0.12 \\
\hline \multicolumn{5}{|l|}{ Temperature $\left({ }^{\circ} \mathrm{C}\right)$} \\
\hline Overhead & 25 & 81.0 & 78.1 & 90.2 \\
\hline Bottom & 25 & 102.3 & 83.6 & 210 \\
\hline Feed $(\mathrm{kg} / \mathrm{h})$ & 10,000 & 10,290 & 1362 & 908 \\
\hline Solvent $(\mathrm{kg} / \mathrm{h})$ & 8,926 & & 535.4 & \\
\hline Make-up (kg/h) & 0.21 & & 0.3 & \\
\hline Recycle (kg/h) & 374 & & & \\
\hline \multicolumn{5}{|l|}{ Product (kg/h) } \\
\hline Overhead & 10,290 & 1,362 & 989 & 374 \\
\hline Bottom & 9,010 & 8,926 & 908 & 534 \\
\hline Reflux (kg/h) & - & 3,995 & 1,232 & 563 \\
\hline Vap. boil up(kg/h) & - & 5,638 & 495 & 578 \\
\hline Cooling duty (MW) & - & -1.24 & -0.38 & -0.28 \\
\hline Reboiler duty (MW) & - & 1.36 & 0.18 & 0.28 \\
\hline Preheat/Cool (MW) & -0.79 & 0.74 & $0.26 /-0.35$ & 0.30 \\
\hline \multicolumn{5}{|l|}{ Comp. (mass frac.) } \\
\hline \multicolumn{5}{|l|}{ Feed } \\
\hline Ethanol & 0.1 & 0.1052 & 0.7926 & 0.1070 \\
\hline Product & Ovhd & Ovhd & Ovhd & Ovhd \\
\hline Ethanol & 0.1052 & 0.7926 & 0.9934 & 0.2598 \\
\hline
\end{tabular}

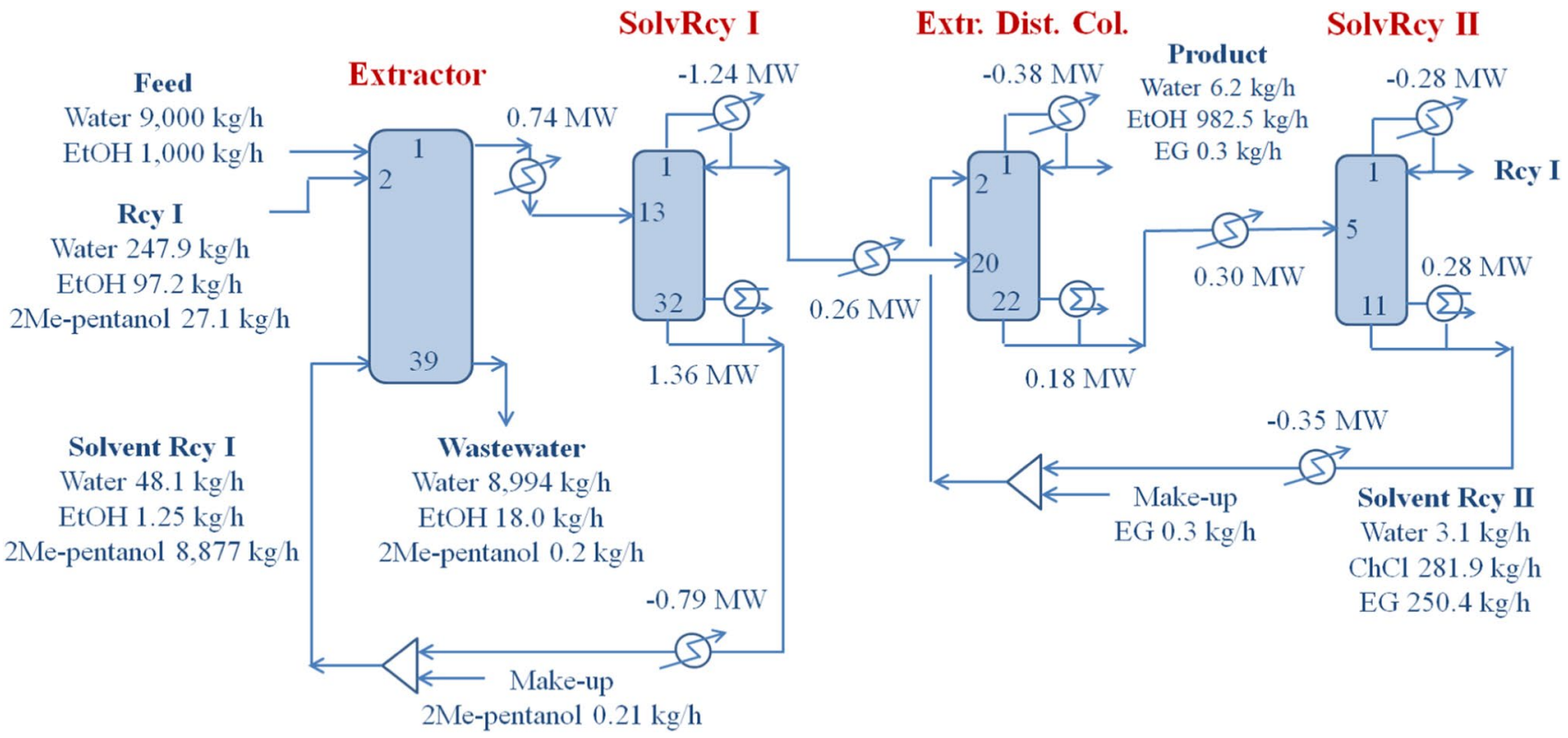

Fig. 3 Process flow diagram of the proposed bioethanol recovery process 
For energy recovery, preheaters were used for feedstock heating in the three distillation columns. Because the bottom temperature in the first solvent recovery column is high and the extractor is operated at near room temperature, $58 \%$ of its reboiler duty is recovered from its cooler. The recovered heat accounts for $55 \%$ of the preheater heat demand. The availability of recovered heat for reuse in the preheaters was evaluated using a heat exchanger network design with pinch technology [56], as shown in Fig. 4. With a pinch temperature of $10{ }^{\circ} \mathrm{C}$, sufficient utility was available for feedstock preheating in the distillation columns.

\subsection{DES entrainer}

The second stage of the process entails distillation to increase the ethanol purity from 79 to $99.3 \%$ after the solvent removal step. The purification process comprises a number of steps, including azeotropic and extractive distillation using various solvents. Although a detailed comparison of the energy demand is given in the following section, the design result for extractive distillation using choline chloride/ethylene glycol as the entrainer is presented in Fig. 5. The extractive distillation column has two feed streams, including the entrainer stream. The entrainer was introduced near the top, and the feed from the first solvent recovery column was near the bottom to obtain the highest ethanol composition in the overhead product, the target product of this project. Most of the water in the feed from the previous

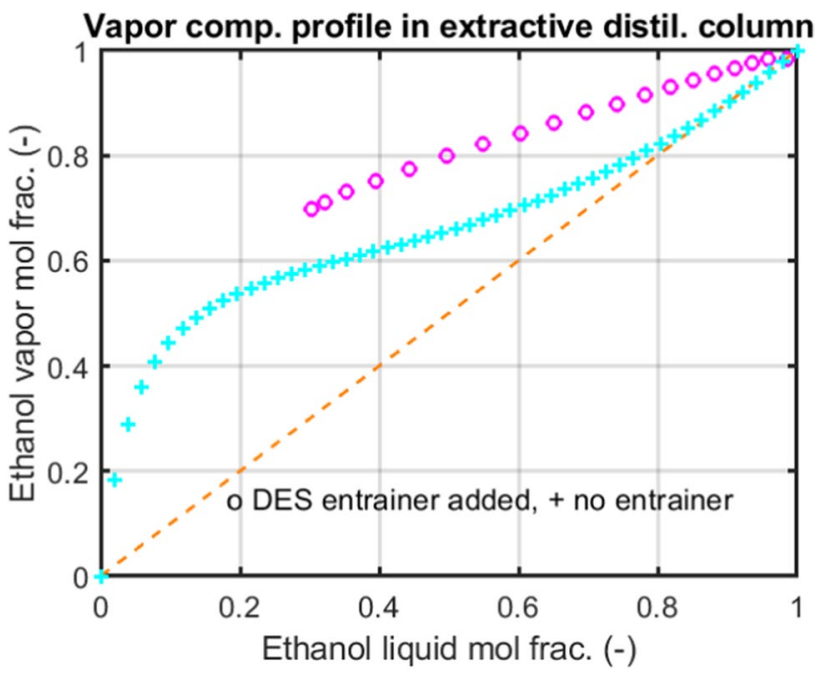

Fig. 5 Vapor composition profiles in the extractive distillation column with and without a deep eutectic solvent entrainer, demonstrating the differences in azeotrope treatment

column was confined to the bottom product, which consisted of water and the entrainer. The entrainer was recovered in solvent recovery column II, and its overhead product, a mixture of water and ethanol, was recycled to the extractor.

Figure 6 depicts the extractive distillation column profile, demonstrating the efficiency of the entrainer in overcoming the ethanol/water azeotrope. The plus symbols in the $x-y$

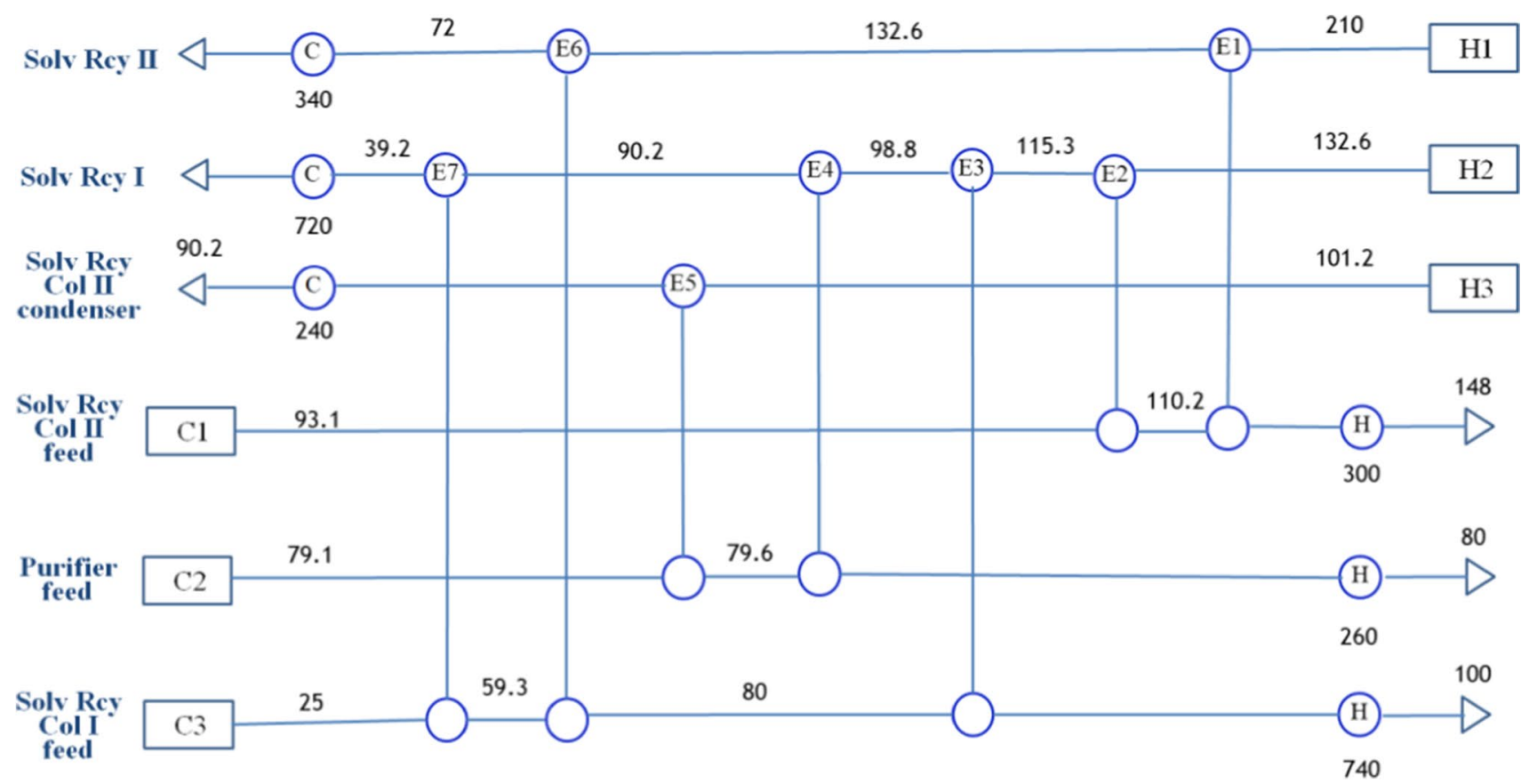

Fig. 4 A diagram of the heat exchanger network for heat recovery. The numbers below the circles represent the heat transfer rate in kW, and those on the lines indicate the temperature in centigrade 


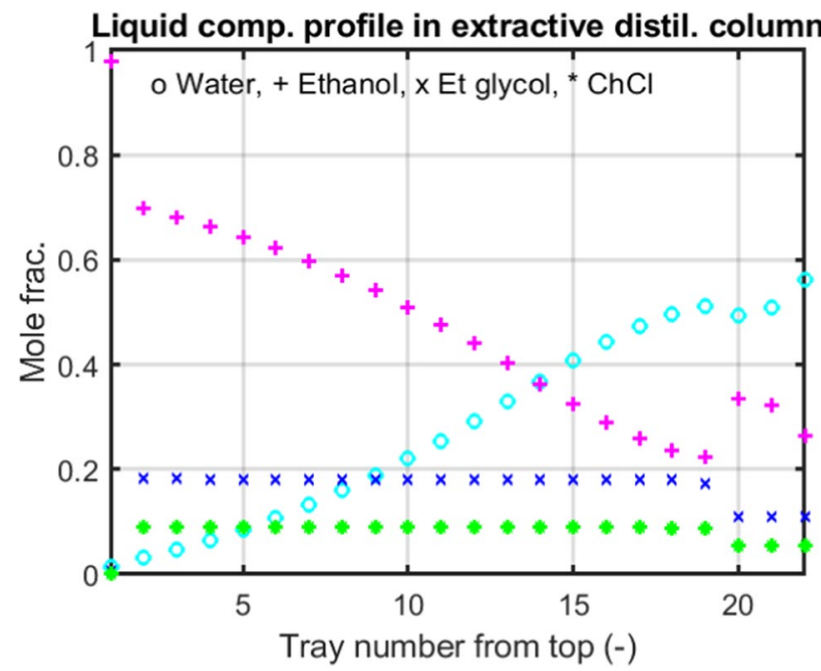

Fig. 6 Column profile for the extractive distillation column

diagram of the ethanol/water mixture without the entrainer show the changes in azeotropic composition at high ethanol contents. The circles indicate higher ethanol vapor compositions compared to liquid compositions. Although ethylene glycol has been utilized previously as an entrainer to concentrate ethanol $[18,57,58]$, the amount used was $>$ fourfold that used in this study for equal ethanol production. Choline chloride/urea (1:2) is another DES that has been used for flash-tank ethanol concentration [30, 59], and in the distillation column [29] for solvent recovery.

\subsection{Performance evaluation}

The performance of the proposed process was evaluated by comparing its energy demands with those of previously reported processes. Because distillation is the most economical and reliable bioethanol recovery approach in large-scale industrial operations, many bioethanol processes apply conventional distillation for pre-processing fermented feedstock, as shown in Table 3. Biowaste generated from biomass pre-treatment during bioethanol fermentation is abundant and can be utilized as an energy source [60]. Extraction has been used as an energy-efficient process for pre-processing fermented beer $[1,36,61]$. At comparable feedstock compositions, the energy demands for pre-processing via distillation and extraction do not differ significantly owing to low solvent extraction efficiencies. Excluding azeotropic distillation with benzene, which has an excessive energy demand, the proposed process requires $25 \%$ less energy compared to the average demand of the previously reported operations listed in Table 3 . The extraction solvent used in this study is more efficient than those used in other extraction processes. The solvent selection guidelines for bioethanol recovery [36] list branched long-chain alcohols as first-choice; the judicious selection of the solvent used in this study was based on its boiling point, which is a crucial factor in the solvent recovery process. Distillation continues to be widely implemented for bioethanol recovery [18-20], despite the high energy demand. The extraction efficiencies of previously used solvents were relatively low, resulting in high energy consumption.

\subsection{Economics}

The investment and operating costs for the extractor and the three distillation columns are listed in Table 4. While the investment includes column and tray costs and the costs of constructing the heat exchangers of the reboiler, condenser, preheater, and cooler, the operating cost represents the steam and water cooling costs. The steam cost was only calculated for reboiler duties because the preheaters use recovered heat.
Table 3 Energy demand comparison among several reported bioethanol purification processes

\begin{tabular}{|c|c|c|c|c|c|}
\hline Pre-processing & Refining & Feed (wt $\%)$ & $\begin{array}{l}\text { Reboiler duty } \\
(\mathrm{MW}) \text { for } \\
\mathrm{t}-\mathrm{EtOH} / \mathrm{h}\end{array}$ & Remark & Ref \\
\hline Distillation & Ethylene glycol ED & 10 & 3.22 & Feed heating & [18] \\
\hline Distillation & Press. swing adsorption & 10 & 2.05 & $\begin{array}{l}\text { PSA electric- } \\
\text { ity not } \\
\text { counted }\end{array}$ & [15] \\
\hline Distillation & Ethylene glycol ED & 11.9 & 1.89 & Feed heating & {$[20]$} \\
\hline Distillation & Ethylene glycol ED & 11.9 & 2.75 & Feed heating & [19] \\
\hline $\begin{array}{l}\text { Extraction } \\
i \text {-octanol }\end{array}$ & Ethylene glycol ED & 11.9 & 2.52 & & [12] \\
\hline $\begin{array}{l}\text { Extraction } \\
n \text {-Dodecane }\end{array}$ & Glycerin ED & 22.1 & 2.03 & & [11] \\
\hline Distillation & Benzene Azeotropic Dist & 3.1 & 18.48 & & [34] \\
\hline $\begin{array}{l}\text { Extraction } \\
\text { 2-Me pentanol }\end{array}$ & Choline Chl./EG ED & 10 & 1.82 & & This study \\
\hline
\end{tabular}


Table 4 Cost evaluation of the proposed recovery process. The units are in million US dollars and the utility cost is per annum

\begin{tabular}{lllll}
\hline Variable & Extractor & SolvRec I & Purifier & SolvRec II \\
\hline Investment & & & & \\
$\quad$ Column & 0.285 & 0.216 & 0.090 & 0.041 \\
$\quad$ Tray & 0.018 & 0.013 & 0.004 & 0.001 \\
$\quad$ Condenser & & 0.140 & 0.037 & 0.026 \\
$\quad$ Reboiler & & 0.250 & 0.116 & 0.095 \\
$\quad$ Preheater/cooler & 0.098 & 0.094 & 0.078 & 0.046 \\
Total & & & & 1.647 \\
Utility & & & & \\
$\quad$ Steam & & 0.507 & 0.067 & 0.037 \\
$\quad$ Coolant & & 0.016 & 0.005 & 0.004 \\
Total & & & & 0.636 \\
\hline
\end{tabular}

The steam cost was $\$ 24 / t$ in 2017 , as estimated by scaling the 2001 price given in [48]. With a cash flow of $59 \%$ of utility cost and a return of investment of $23 \%$ at $7 \%$ interest rate, the payback time was 4.7 year at a discount rate of $21.4 \%$ [62]. Considering operation for 300 days per year, the bioethanol production cost via recovery is US $\$ 0.10 / \mathrm{L}$ ethanol. This recovery cost is comparable to previously reported total production costs of US $\$ 0.66 / \mathrm{L}$ ethanol [63], US $\$ 0.84 / \mathrm{L}$ ethanol [64], and US\$0.77/L ethanol [65]. The downstream recovery cost was in the range of 30-40\% of the total biofuel production costs [66]. The recovery cost was compared to those of several reported processes, as listed in Table 5. The cost of the proposed process is $10 \%$ less than the average cost of five previously reported processes listed in the table, excluding the exceptionally high-cost example.

The National Renewable Energy Laboratory (NREL) of the US Department of Energy examined bioethanol production from milled corn stover [67]. The study entailed a practical technoeconomic evaluation that included cost estimation, and a process was developed with the guidance of Harris Group Inc., consultants with hands-on experience in commercial bioethanol plant engineering. The separation and purification costs reported in the above study were compared with those estimated herein. The reported 22.9 ton/h bioethanol production project entailed the use of two distillation columns and a molecular sieve adsorption tower for dehydration. The capital cost of the project was $\$ 26.98 \mathrm{~m}$, equating to $\$ 2.73 \mathrm{~m}$ when a scaling-up exponent of 0.68 is applied [68]. Meanwhile, the investment cost of the proposed process is $\$ 1.65 \mathrm{~m}$, which is a reasonable improvement considering the higher solvent extraction efficiency.

\section{Conclusions}

Distillation is commonly applied for bioethanol recovery from fermentation broth as it is the most economical and reliable approach for large-scale industrial production. Preprocessing of low-content bioethanol was achieved via solvent extraction instead of conventional distillation to reduce the energy demand, and the product was concentrated via extractive distillation using a deep eutectic solvent to overcome the azeotrope of the ethanol/water mixture. Thus, a bioethanol recovery process entailing the combination of extraction pretreatment and extractive distillation using choline chloride/ethylene glycol (1:2) was designed and optimized for energy efficiency. The energy demand of the developed process was $25 \%$ less than the average demand of several previously reported processes. Furthermore, the proposed process is more cost efficient than the currently used processes.

\section{Abbreviations}

DES: Deep eutectic solvent; FID: Flame ionization detector; LLE: Liquid-liquid equilibrium; NRTL: Non-random two-liquid; TAC: Total annualized cost; VLE: Vaporliquid equilibrium

\section{List of symbols}

$a$ : Binary interaction parameter (-); $b$ : Binary interaction parameter (-); $k$ : Potential constant (-); $N$ : Number of components (-); $P$ : Pressure (Pa); $r$ : Position vector (-); $T$ : Temperature (K); $x$ : Liquid composition (-); $y$ : Vapor composition (-); $\alpha$ : Non-randomness factor (-); $\varphi$ : Fugacity
Table 5 Recovery cost comparison among various processes. The units are in million US dollars, and the utility cost is per annum. The payback time is 4.7 years at a discount rate of $21.4 \%$

\begin{tabular}{llrllll}
\hline Pre-processing & Investment & Utility & Capacity $(\mathrm{t} / \mathrm{h})$ & Cost $(\$ / \mathrm{kg})$ & Remark & Ref \\
\hline Distillation & 5.70 & 15.26 & 12.5 & 0.18 & Feed heating & {$[18]$} \\
Distillation & 2.21 & 2.80 & 3.9 & 0.12 & Feed heating & {$[20]$} \\
Distillation & 4.97 & 10.46 & 9.94 & 0.16 & Feed heating & {$[19]$} \\
Extraction & 0.42 & 0.10 & 0.04 & 0.66 & & {$[12]$} \\
$\begin{array}{l}\text {-octanol } \\
\text { Extraction }\end{array}$ & 0.39 & 0.16 & 0.21 & 0.16 & & {$[11]$} \\
$\begin{array}{l}n \text {-Dodecane } \\
\text { Extraction }\end{array}$ & 1.65 & 0.64 & 0.99 & 0.14 & & \\
2-Me pentanol & & & & & & \\
\hline
\end{tabular}


coefficient (-) or torsion angle $\left(^{\circ}\right) ; \gamma$ : Activity coefficient $(-) ; \theta$ : Band angle $\left(^{\circ}\right.$

\section{Subscripts \\ $i$ : Component $\mathrm{i} ; j$ : Component $\mathrm{j}$}

Supplementary Information The online version contains supplementary material available at https://doi.org/10.1007/s13399-021-02213-2.

Acknowledgements This study received financial support from the Basic Science Research Program through the National Research Foundation of Korea (2021R1A2C2094256) and from the Korea Institute of Energy Technology Evaluation and Planning (20194010201840).

Open Access This article is licensed under a Creative Commons Attribution 4.0 International License, which permits use, sharing, adaptation, distribution and reproduction in any medium or format, as long as you give appropriate credit to the original author(s) and the source, provide a link to the Creative Commons licence, and indicate if changes were made. The images or other third party material in this article are included in the article's Creative Commons licence, unless indicated otherwise in a credit line to the material. If material is not included in the article's Creative Commons licence and your intended use is not permitted by statutory regulation or exceeds the permitted use, you will need to obtain permission directly from the copyright holder. To view a copy of this licence, visit http://creativecommons.org/licenses/by/4.0/.

\section{References}

1. Busic A, Mardetko N, Kundas S, Morzak G, Belskaya H, Santek MI, Komes D, Novak S, Santek B (2018) Bioethanol production from renewable raw materials and its separation and purification: a review. Food Technol Biotechnol 56:289-311. https://doi.org/ 10.17113/ftb.56.03.18.5546

2. Atasoy M, Owusu-Agyeman I, Plaza E, Cetecioglu Z (2018) Bio-based volatile fatty acid production and recovery from waste streams: current status and future challenges. Bioresour Technol 268:773-786. https://doi.org/10.1016/j.biortech.2018.07.042

3. Ji XJ, Huang H, Ouyang PK (2011) Microbial 2,3-butanediol production: a state-of-the-art review. Biotechnol Adv 29:351-364. https://doi.org/10.1016/j.biotechadv.2011.01.007

4. Li QZ, Jiang XL, Feng XJ, Wang JM, Sun C, Zhang HB, Xian M, Liu HZ (2016) Recovery processes of organic acids from fermentation broths in the biomass-based industry. J Microbiol Biotechnol 26:1-8. https://doi.org/10.4014/jmb.1505.05049

5. Baroi GN, Gavala HN, Westermann P, Skiadas IV (2017) Fermentative production of butyric acid from wheat straw: economic evaluation. Ind Crop Prod 104:68-80. https://doi.org/10.1016/j. indcrop.2017.04.008

6. Oseguera-Villasenor I, Martinez-Rodriguez G, Barroso-Munoz FO, Segovia-Hernandez JG, Hernandez S (2018) Multiplicities in dividing wall distillation columns in the purification of bioethanol: energy considerations. Clean Technol Envir 20:1631-7. https:// doi.org/10.1007/s10098-017-1415-0

7. Woldemariam D, Kullab A, Khan EU, Martin A (2018) Recovery of ethanol from scrubber-water by district heat-driven membrane distillation: industrial-scale technoeconomic study. Renew Energ 128:484-494. https://doi.org/10.1016/j.renene.2017.06.009
8. Loulergue P, Balannec B, Fouchard-Le Graet L, Cabrol A, Sayed W, Djelal H, Amrane A, Szymczyk A (2019) Air-gap membrane distillation for the separation of bioethanol from algal-based fermentation broth. Sep Purif Technol 213:255-263. https://doi.org/ 10.1016/j.seppur.2018.12.047

9. Gros HP, Diaz S, Brignole EA (1998) Near-critical separation of aqueous azeotropic mixtures: process synthesis and optimization. J Supercrit Fluid 12:69-84

10. Paulo CI, Diaz MS, Brignole EA (2012) Minimizing costs in nearcritical bioethanol extraction and dehydration processes. Energ Fuel 26:3785-3795. https://doi.org/10.1021/ef3002907

11. Martinez AA, Saucedo-Luna J, Segovia-Hernandez JG, Hernandez S, Gomez-Castro FI, Castro-Montoya AJ (2012) Dehydration of bioethanol by hybrid process liquid-liquid extraction/extractive distillation. Ind Eng Chem Res 51:5847-5855. https://doi.org/10.1021/ie200932g

12. Vazquez-Ojeda M, Segovia-Hernandez JG, Hernandez S, Hernandez-Aguirre A, Kiss AA (2013) Design and optimization of an ethanol dehydration process using stochastic methods. Sep Purif Technol 105:90-97. https://doi.org/10.1016/j.seppur.2012. 12.002

13. Lee SC, Woo HC, Kim YH (2021) Energy-efficient ethanol recovery process using 2-methyl pentanol extraction. Fuel. https://doi. org/10.1016/j.fuel.2021.122393

14. Jeong JS, Jeon H, Ko KM, Chung B, Choi GW (2012) Production of anhydrous ethanol using various PSA (pressure swing adsorption) processes in pilot plant. Renew Energ 42:41-45. https://doi. org/10.1016/j.renene.2011.09.027

15 Loy YY, Lee XL, Rangaiah GP (2015) Bioethanol recovery and purification using extractive dividing-wall column and pressure swing adsorption: an economic comparison after heat integration and optimization. Sep Purif Technol 149:413-27. https://doi.org/ 10.1016/j.seppur.2015.06.007

16. Singh A, da Cunha S, Rangaiah GP (2019) Heat-pump assisted distillation versus double-effect distillation for bioethanol recovery followed by pressure swing adsorption for bioethanol dehydration. Sep Purif Technol 210:574-586. https://doi.org/10.1016/j. seppur.2018.08.043

17. Granjo JFO, Nunes DS, Duarte BPM, Oliveira NMC (2020) A comparison of process alternatives for energy-efficient bioethanol downstream processing. Sep Purif Technol 238:116414. https:// doi.org/10.1016/j.seppur.2019.116414

18. Kiss AA, Ignat RM (2012) Innovative single step bioethanol dehydration in an extractive dividing-wall column. Sep Purif Technol 98:290-297. https://doi.org/10.1016/j.seppur.2012.06.029

19. Errico M, Rong BG (2012) Synthesis of new separation processes for bioethanol production by extractive distillation. Sep Purif Technol 96:58-67. https://doi.org/10.1016/j.seppur.2012.05.022

20. Errico M, Rong BG, Tola G, Spano M (2013) Optimal synthesis of distillation systems for bioethanol separation. Part 1: Extractive Distillation with Simple Columns. Ind Eng Chem Res 52:16121619. https://doi.org/10.1021/ie301828d

21. Verma R, Naik PK, Diaz I, Banerjee T (2021) Separation of low molecular weight alcohols from water with deep eutectic solvents: liquid-liquid equilibria and process simulations. Fluid Phase Equilibr 533:112949. https://doi.org/10.1016/j.fluid.2021.112949

22. Zhao YT, Ma K, Bai WT, Du DQ, Zhu ZY, Wang YL, Gao J (2018) Energy-saving thermally coupled ternary extractive distillation process by combining with mixed entrainer for separating ternary mixture containing bioethanol. Energy 148:296-308. https://doi.org/10.1016/j.energy.2018.01.161

23. Yang A, Su Y, Chien IL, Jin SM, Yan CL, Wei SA, Shen WF (2019) Investigation of an energy-saving double-thermally coupled extractive distillation for separating ternary system benzene/ toluene/cyclohexane. Energy 186:115756. https://doi.org/10. 1016/j.energy.2019.07.086 
24. Sun SR, Chun W, Yang A, Shen WF, Cui PZ, Ren JZ (2020) The separation of ternary azeotropic mixture: thermodynamic insight and improved multi-objective optimization. Energy 206:118117. https://doi.org/10.1016/j.energy.2020.118117

25. Chen Z, Dai Y, Chi S, Su Z, Xing J, Wang Y, Lu Y (2021) Analysis and intensification of energy saving process for separation of azeotrope by ionic liquid extractive distillation based on molecular dynamics simulation. Sep Purif Technol 276:119254. https://doi. org/10.1016/j.seppur.2021.119254

26. Zhang Y, Fang J, Zhang L (2019) Isobaric vapor-liquid equilibria for the quaternary system water + ethanol + ethylene glycol + choline chloride and the ternary system water + ethanol + choline chloride at 101.3 kPa. J Chem Eng Data 64:2894-2903. https:// doi.org/10.1021/acs.jced.9b00254

27. Shu G, Tan Y, Cui L, Zhang Y, Zhang L (2020) Effect of mixed solvents containing ethylene glycol and various salts on the vapor-liquid equilibrium of water + methanol + ethanol. J Chem Eng Data 65:3029-3036. https://doi.org/10.1021/acs. jced.0c00057

28. Peng Y, Lu X, Liu B, Zhu J (2017) Separation of azeotropic mixtures (ethanol and water) enhanced by deep eutectic solvents. Fluid Phase Equilibr 448:128-134. https://doi.org/10. 1016/j.fluid.2017.03.010

29. Dongmin H, Yanhong C (2018) Combining the preconcentration column and recovery column for the extractive distillation of ethanol dehydration with low transition temperature mixtures as entrainers. Chem Eng Process 131:203-214. https://doi.org/ 10.1016/j.cep.2018.08.005

30. Shang X, Ma S, Pan Q, Li J, Sun Y, Ji K, Sun L (2019) Process analysis of extractive distillation for theseparation of ethanolwater using deep eutectic solvent as entrainer. Chem Eng Res Des 148:298-311. https://doi.org/10.1016/j.cherd.2019.06.014

31. Li P, Wu Y, Hao X, Zhang L (2021) Performance of the glycerol-choline chloride deep eutectic solvent as an entrainer for separation of ethanol and water. J Chem Eng Data 66:31013106. https://doi.org/10.1021/acs.jced.1c00207

32. Lee SC, Woo HC, Kim YH (2021) Energy-efficient recovery process of 2,3-butanediol using 2-heptanol extraction. Chem Eng Process 160:108286. https://doi.org/10.1016/j.cep.2020. 108286

33. Oh HW, Lee SC, Woo HC, Kim YH (2021) Energy-efficient biobutanol recovery process using 1-heptanol extraction. Chem Eng Technol 44.https://doi.org/10.1002/ceat.202100154

34. Alzate CAC, Toro OJS (2006) Energy consumption analysis of integrated flowsheets for production of fuel ethanol from lignocellulosic biomass. Energy 31:2447-2459. https://doi.org/ 10.1016/j.energy.2005.10.020

35. Carvalho PJ, Khan I, Morais A, Granjo JFO, Oliveira NMC, Santos LMNBF, Coutinho JAP (2013) A new microebulliometer for the measurement of the vapor-liquidequilibrium of ionic liquid systems. Fluid Phase Equilibr 354:156-165. https://doi. org/10.1016/j.fluid.2013.06.015

36. Vane LM (2008) Separation technologies for the recovery and dehydration of alcohols from fermentation broths. Biofuel Bioprod Bior 2:553-588. https://doi.org/10.1002/bbb.108

37. Paixao SM, Alves L, Pacheco R, Silva CM (2018) Evaluation of Jerusalem artichoke as a sustainable energy crop to bioethanol: energy and $\mathrm{CO}(2)$ eq emissions modeling for an industrial scenario. Energy 150:468-481. https://doi.org/10.1016/j.energy. 2018.02.145

38. Aspentech (2015) Aspen Engineering Suite. Aspen Technology Inc, Bedford

39. Renon H, Prausnitz JM (1968) Local compositions in thermodynamic excess functions for liquid mixtures. AIChE J $14: 135-144$
40. Niskanen J, Henschel H Molecular dynamics simulations. www. courses.physics.helsinki.fi/fys/moldyn/. Accessed 30 August 2021

41. Rai N, Siepmann JI (2013) Transferable potentials for phase equilibria. 10. Explicit-Hydrogen Description of Substituted Benzenes and Polycyclic Aromatic Compounds. J Phys Chem B 117:273288. https://doi.org/10.1021/jp307328x

42. Dubbeldam D, Calero S, Ellis DE, Snurr RQ (2015) RASPA 2.0: molecular software package for adsorption and diffusion in (flexible) nanoporous materials. raspa_instruction.pdf Accessed 21 October 2021 https://github.com/numat/RASPA2/blob/master/ Docs/raspa.pdf

43. Dubbeldam D, Calero S, Ellis DE, Snurr RQ (2016) RASPA: molecular simulation software for adsorption and diffusion in flexible nanoporous materials. Mol Simul 42:81-101. https://doi.org/ 10.1080/08927022.2015.1010082

44. Cho JH, Kim YH (2018) Molecular simulation-assisted solvent selection for separation of 1,2,4-trimethylbenzene. Chem Eng Technol 41:1913-1920

45. Seo CH, Kim YH (2019) Separation of ethylbenzene and p-xylene using extractive distillation with p-dinitrobenzene. Sep Purif Technol 209:1-5

46. Woo HC, Kim YH (2019) Solvent selection for extractive distillation using molecular simulation. AIChE J 65:e16665. https://doi. org/10.1002/aic. 16665

47. Rahbari A, Garcia-Navarro JC, Ramdin M, van den Broeke LJP, Moultos OA, Dubbeldam D, Vlugt TJH (2021) Effect of water content on thermodynamic properties of compressed hydrogen. $\mathrm{J}$ Chem Eng Data 66:2071-2087. https://doi.org/10.1021/acs.jced. $1 \mathrm{c} 00020$

48. Turton R, Baille RC, Whiting WB, Shaeiwitz JA (2003) Analysis, synthesis, and design of chemical processes, 2nd edn. Prentice Hall, Upper Saddle River

49. Domingues L, Pinheiro CIC, Oliveira NMC (2017) Economic comparison of a reactive distillation-based process with the conventional process for the production of ethyl tert-butyl ether (ETBE). Comput Chem Eng 100:9-26. https://doi.org/10.1016/j. compchemeng.2017.01.008

50. Kokare MB, Ranjani V, Mathpati CS (2018) Response surface optimization, kinetic study and process design of n-butyl levulinate synthesis. Chem Eng Res Des 137:577-588. https://doi.org/ 10.1016/j.cherd.2018.07.036

51. Singh A, Rangaiah GP (2017) Review of technological advances in bioethanol recovery and dehydration. Ind Eng Chem Res 56:5147-5163. https://doi.org/10.1021/acs.iecr.7b00273

52. Rocha JA, Cárdenas JC, Sosa C, aJR, (1989) Preliminary design of sieve tray extraction columns. 1. Determination of the Column Diameter. Flooding Velocities in Sieve Tray Extractors. Ind Eng Chem Res 28:1873-1878

53. NIH Hazard Classes and Categories, 2-Methyl-1-pentanol. https:// pubchem.ncbi.nlm.nih.gov/compound/2-Methyl-1-pentanol\#secti on=Hazard-Classes-and-Categories. Accessed 30 August 2021

54. Offeman RD, Stephenson SK, Franqui D, Cline JL, Robertson GH, Orts WJ (2008) Extraction of ethanol with higher alcohol solvents and their toxicity to yeast. Sep Purif Technol 63:444-451

55. Murphy TK, Blanch HW, Wilke CR (1982) Water recycling in extractive fermentation. Process Biochem 17:6-9

56. Kemp IC (2007) Pinch analysis and process integration, 2nd edn. Butterworth-Heinemann, Burlington

57. Ravagnani MASS, Reis MHM, Filho RM, Wolf-Maciel MR (2010) Anhydrous ethanol production by extractive distillation: a solvent case study. Process Saf Environ Protect 88:67-73. https:// doi.org/10.1016/j.psep.2009.11.005

58. Li G, Bai P (2012) New operation strategy for separation of ethanol-water by extractive distillation. Ind Eng Chem Res 51:27232729. https://doi.org/10.1021/ie2026579 
59. Pan Q, Shang X, Li J, Ma S, Li L, Sun L (2019) Energy-efficient separation process and control scheme for extractive distillation of ethanol-water using deep eutectic solvent. Sep Purif Technol 219:113-126. https://doi.org/10.1016/j.seppur.2019.03.022

60. Fonseca GC, Costa CBB, Cruz AJG (2020) Economic analysis of a second-generation ethanol and electricity biorefinery using superstructural optimization. Energy 204:117988. https://doi.org/ 10.1016/j.energy.2020.117988

61. Weilnhammer C, Blass E (1994) Continuous Fermentation with Product Recovery by in-situ Extraction. Chem Eng Technol 17:365-373

62. Achinas S, Leenders N, Krooneman J, Euverink GJW (2019) Feasibility assessment of a bioethanol plant in the Northern Netherlands. Appl Sci 9:4586. https://doi.org/10.3390/app9214586

63. Solarte-Toro JC, Romero-Garcia JM, Susmozas A, Ruiz E, Castro E, Cardona-Alzate CA (2019) Techno-economic feasibility of bioethanol production via biorefinery of olive tree prunings (OTP): optimization of the pretreatment stage. Holzforschung 73:3-13. https://doi.org/10.1515/hf-2018-0096

64. Ou LW, Brown TR, Thilakaratne R, Hu GP, Brown RC (2014) Techno-economic analysis of co-located corn grain and corn stover ethanol plants. Biofuel Bioprod Bior 8:412-422. https:// doi.org/10.1002/bbb.1475

65. Garcia-Velasquez CA, Cardona CA (2019) Comparison of the biochemical and thermochemical routes for bioenergy production: a techno-economic (TEA), energetic and environmental assessment. Energy 172:232-242. https://doi.org/10.1016/j.energy.2019.01. 073

66. Bekatorou A, Dima A, Tsafrakidou P, Boura K, Lappa K, Kandylis P, Pissaridi K, Kanellaki M, Koutinas AA (2016) Downstream extraction process development for recovery of organic acids from a fermentation broth. Bioresour Technol 220:34-37. https://doi. org/10.1016/j.biortech.2016.08.039

67 Humbird D, Davis R, Tao L, Kinchin C, Hsu D, Aden A (2011) Process design and economics for biochemical conversion of lignocellulosic biomass to ethanol. National Renewable Energy Laboratory, Golden

68. Aden A, Ruth M, Ibsen K, Jechura J, Neeves K, Sheehan J, Wallace B, Montague L, Slayton A, Lucas J (2002) Lignocellulosic biomass to ethanol process design and economics utilizing cocurrent dilute acid prehydrolysis and enzymatic hydrolysis for corn stover. National Renewable Energy Laboratory, Golden

Publisher's note Springer Nature remains neutral with regard to jurisdictional claims in published maps and institutional affiliations. 